\title{
Confidence, Crashes and Animal Spirits
}

\author{
Roger E.A. Farmer ${ }^{1}$ \\ Department of Economics, UCLA \\ 8283 Bunche Hall \\ Box 951477 \\ Los Angeles CA 90095-1477 \\ rfarmer@econ.ucla.edu
}

First Version: May 2009.

This version: January 31, 2011

\footnotetext{
${ }^{1}$ The author gratefully acknowledges the support of NSF grant 0720839. I wish to thank Katrin Assenmacher-Wesche, Amy Brown, Larry Christiano, Anton Cheremukhin, Alain Delacroix, Gauti Eggersston, Martin Ellison, Marco Guerrazzi, Peter Howitt, Masanori Kashiwagi, James Nason, Roberto Perotti, Valery Ramey and Andrew Scott for their comments on an earlier version of this paper and on a related paper that influenced the final draft. I also wish to thank three referees of this journal for their insightful comments.
} 


\begin{abstract}
This paper presents a model of the macroeconomy that reformulates what I take to be two important ideas from Keynes General Theory. The first is that there may be a continuum of steady state unemployment rates. The second is that beliefs select an equilibrium. I argue that search and matching costs in the labor market lead to the existence of a continuum of equilibria and I resolve the resulting indeterminacy by assuming that the beliefs of stock market participants are self-fulfilling. The paper reconciles Keynesian economics with general equilibrium theory without invoking the assumption of frictions that prevent wages and prices from reaching their equilibrium levels.
\end{abstract}




\section{Introduction}

This paper is an attempt to reformulate what I take to be two key insights from Keynes' General Theory (Keynes, 1936). The first is that there is something profoundly different about the labor market from most other markets in the economy. The second is that the beliefs of participants in the asset markets have an independent influence on economic activity. In the language of modern dynamic general equilibrium theory, we would say that there is a continuum of labor market equilibria and that beliefs about the value of the stock market select an equilibrium.

The General Theory contains many ideas, some of which are internally inconsistent, and Keynes did not try to reconcile his theory with Walrasian economics. That task was carried out by a group of interpreters including Alvin Hansen (1936) and John Hicks (1937). The current dominant paradigm, new-Keynesian economics, originated with the third edition of Paul Samuelson's (1955) undergraduate textbook in which he introduced the idea of the neoclassical synthesis. According to this doctrine, the economy is Keynesian in the short run but classical in the long run. The short run is defined as the period over which not all prices have had time to adjust to their Walrasian levels.

This paper introduces a different interpretation of the key ideas from the General Theory. ${ }^{1}$ Although my work is inspired by Keynesian economics, this paper is not about the history of thought. I offer a way of formulating the idea that market economies are not inherently self-stabilizing without assuming that prices or wages are prevented from adjusting to their equilibrium levels

\footnotetext{
${ }^{1}$ The first paper to discuss the equilibrium concept that I use here is Farmer (2008b) and the concept is defined formally in Farmer (2010b). Related papers include Farmer (2010c) and Farmer and Plotnikov (2010) which explore the role of fiscal policy in the oldKeynesian framework, Guerrazzi (2010) which uses a version of the old-Keynesian model to resolve Shimer's 2005 puzzle and Gelain and Guerrazzi (2010) and Farmer (2010a) which estimate the old-Keynesian model using Bayesian methods. The old-Keynesian equilibrium concept is extended to models with multiple commodities in Farmer (2008a).
} 
by some kind of friction. Instead, I claim that high, persistent unemployment is a potentially permanent feature of a market economy in a steady state equilibrium.

\section{Relationship with Standard Search Models}

Peter Diamond (1982a, 1984) pointed out that labor search models often contain multiple equilibria. These multiplicities exist for two reasons. The first has to do with externalities in the recruiting process of the kind studied by Diamond (1982b), Mortensen (1984) and Pissarides (1984). The second has to do with a bilateral monopoly problem. Howitt and McAfee (1987) pointed out that this second problem leads, not just to a finite multiplicity of equilibria, but to the existence of a continuum of steady state unemployment rates.

The response in the literature to the Howitt-McAfee indeterminacy has been to argue that the labor search model requires the addition of an equation based on preferences, technology and endowments. A variety of candidates have been proposed. The most common is the Nash bargaining solution that allocates rents between a firm and a worker by assuming a fixed bargaining weight. This solution was widely perceived to be problematic after Shimer (2005) showed that it leads to unreasonably small fluctuations in unemployment, relative to the data, if the model is driven by productivity shocks.

Following Shimer's observation, a variety of alternatives have been proposed to the standard Nash bargaining approach including low worker bargaining weight by Hagerdorn and Manovskii (2008), and predetermined wages by Farmer and Hollenhorst (2004) and Hall (2005a, 2005b). The predetermined wage approach was developed further by Hall and Milgrom (2008), Gertler and Trigari (2009) and Gertler, Sala and Trigari (2008), who added more complicated dynamic bargaining structures to explain the observed sluggish movement of wages in data. 
In this paper, I propose a new approach. Instead of searching for a fundamental explanation to close an indeterminate model of the labor market, I close the model with the assumption that firms produce as many goods as are demanded. Demand, in turn, depends on beliefs of market participants about the future value of assets. By embedding the indeterminate labor search market into an asset pricing model, I show that the unemployment rate can be explained as a steady state equilibrium where the indeterminacy of equilibrium is resolved by assuming that the beliefs of market participants are self-fulfilling.

To better understand what I am proposing I am going to begin by studying what is already familiar. I will look at a neoclassical model that is widely used to think about asset pricing. In Section 6 I will alter this model by introducing an alternative model of the labor market. By contrasting the two models, I hope the reader will gain a clear grasp of what I believe to be an important difference in my approach that concerns the link between the asset markets and the labor market. In both old-Keynesian and classical economics, the value of stock market is equal to the net present value of the dividends produced by the corporate sector. But in old-Keynesian economics the link operates from asset prices to dividends rather than the other way around.

\section{Households in a Neoclassical Model}

I assume a representative household that maximizes the following expected utility function,

$$
J=E_{0}\left\{\sum_{t=0}^{\infty} \beta^{t}\left[\log C_{t}-\frac{L_{t}^{1+\gamma}}{1+\gamma}\right]\right\} .
$$

Households earn a money wage $w_{t}$ each period, pay $p_{t}$ for consumption $C_{t}$ and borrow and lend at nominal interest rate $i_{t} \cdot{ }^{2}$ They face the sequence

\footnotetext{
${ }^{2}$ Throughout this paper I will measure prices in units of account that I call dollars.
} 
of budget constraints

$$
A_{t+1}+p_{t} C_{t} \leq\left(1+i_{t-1}\right) A_{t}+w_{t} L_{t}
$$

where $A_{t}$ is net financial assets. In addition, the net present value of consumption is bounded by the net present value of household wealth. ${ }^{3}$

The solution to this problem is characterized by the following Euler equation,

$$
\frac{1}{C_{t}}=E_{t} \beta\left\{\frac{1}{C_{t+1}} \frac{p_{t}}{p_{t+1}}\left(1+i_{t}\right)\right\},
$$

the first order condition for labor supply,

$$
C_{t} L_{t}^{\gamma}=\frac{w_{t}}{p_{t}}
$$

and the transversality condition,

$$
\lim _{t \rightarrow \infty} E_{0}\left\{\frac{\beta}{C_{t+1}} A_{t+1}\right\}=0 .
$$

\section{Production in a Neoclassical Model}

Consumption goods are produced from the technology,

$$
C_{t}=S_{t} K_{t}^{a} L_{t}^{b}
$$

where

$$
a+b=1 .
$$

Since all the models I will study are purely real, the models will determine only relative prices.

${ }^{3}$ Since I assume that there is a representative household, the solution to this problem with a single financial asset is identical to the complete market solution. Adding additional assets serves only to define the values of the relevant Arrow securities. 
There is a single unit of non-reproducible capital and a stochastic time varying productivity parameter $S_{t}$. The competitive assumption implies

$$
\begin{aligned}
\frac{w_{t}}{p_{t}} L_{t} & =b C_{t}, \\
\frac{r r_{t}}{p_{t}} K_{t} & =a C_{t},
\end{aligned}
$$

where $r r_{t}$ is the money rental rate and since I assume that $K_{t}$ is the only storable asset and this is a closed economy, the total financial assets of the household sector, $A_{t}$, are equal to the nominal value of the capital stock,

$$
A_{t}=p_{k, t} K_{t},
$$

where $p_{k, t}$ is the dollar price of capital. The assumption that capital is non reproducible implies that,

$$
K_{t}=1 .
$$

\section{$5 \quad$ Characterizing Equilibria}

The following equations characterize the prices and quantities that occur in a competitive equilibrium;

$$
\begin{gathered}
\frac{1}{C_{t}}=\beta E_{t}\left\{\frac{1}{C_{t+1}} \frac{p_{t}}{p_{t+1}}\left(1+i_{t}\right)\right\}, \\
\left(1+i_{t}\right) E_{t}\left\{\frac{1}{C_{t+1}} \frac{p_{t}}{p_{t+1}}\right\}=E_{t}\left\{\frac{1}{C_{t+1}} \frac{p_{t}}{p_{t+1}}\left(\frac{p_{k, t+1}+r r_{t+1}}{p_{k, t}}\right)\right\}, \\
C_{t} L_{t}^{\gamma}=\frac{w_{t}}{p_{t}}, \\
b \frac{C_{t}}{L_{t}}=\frac{w_{t}}{p_{t}}, \\
C_{t}=\left(S_{t} L_{t}\right)^{b},
\end{gathered}
$$




$$
\frac{r r_{t+1}}{p_{t+1}}=a C_{t+1}
$$

Equation (12) is the consumption Euler equation. Equation (13) is a no-arbitrage condition that sets the expected return on capital, adjusted for covariance with consumption, equal to the interest rate. Equations (14) and (15) are the intratemporal first order conditions for labor for the household and the firm. Equation (16) is the production function and Equation (17) is the first order condition for capital from the firm's maximization problem.

How are these equations solved to determine the behavior of prices and quantities in a competitive equilibrium? To determine employment, we may combine equations (14) and (15) to give the expression

$$
L_{t}=b^{\frac{1}{\gamma+1}}
$$

From the production function and the fact that there is one unit of capital it follows that

$$
C_{t}=\left(S_{t} L_{t}\right)^{b}
$$

By combining (12), (13) and (17) and iterating the resulting equation forwards we may obtain an expression for the relative price of capital in terms of the consumption good,

$$
\frac{p_{k, t}}{p_{t}}=\theta C_{t}
$$

where

$$
\theta \equiv \frac{\beta a}{1-\beta}
$$

From equations (15) and (17) the real wage and the real rental rate are given by the expressions,

$$
\frac{w_{t}}{p_{t}}=b \frac{C_{t}}{L_{t}}
$$

and

$$
\frac{r r_{t}}{p_{t}}=a C_{t}
$$


This model is familiar from the asset pricing literature. Suppose, for example, that productivity shocks follow the following geometric random walk,

$$
S_{t}=S_{t-1} \exp \left(e_{t}\right),
$$

where $e_{t}$ is an iid mean zero random variable. Since $L_{t}$ is given from Equation (18), it follows from (19) that real GDP, equal to $C_{t}$, will also follow a random walk and from (23), the value of rental payments will be proportional to GDP.

As with any model with efficient financial markets and rational investors, the model predicts that the value of a financial asset is equal to the net present value of its dividend stream. If we associate $r r_{t}$ with dividend payments and $p_{k, t}$ with the value of the stock market, the model predicts that

$$
p_{k, t}=\frac{\beta}{1-\beta} r r_{t} .
$$

Since $r r_{t}$ is proportional to GDP and GDP is driven by productivity shocks, fluctuations in $S_{t}$ will be reflected in stock market prices. Different assumptions about preferences and different assumptions about the process that drives $S_{t}$ will lead to more complicated forms of this expression. But the basic idea remains. The value of the stock market is determined by the fundamentals that govern the stochastic productivity process.

\section{Labor Markets with Search}

The environment I have described is one that will be familiar to most readers of this article. In this section I will modify the structure of the labor market by introducing search. I begin by describing the environment and solving a social planning problem. Later, I will describe two different concepts of equilibrium in the search economy. One is a model that is closed by assuming that the real wage is determined by a Nash bargain. The other uses selffulfilling beliefs about the value of assets to determine employment. 
To describe the search economy I modify the utility function by assuming that leisure does not give disutility. This modification allows me to lay stress on the extensive margin when I describe employment fluctuations. It is possible to allow for variable participation rates and variable hours but I have not added those complications since they would obscure the main message of the paper: In an economy with search, there may exist a continuum of equilibria.

The utility function I will study takes the form,

$$
J=E_{0}\left\{\sum_{t=0}^{\infty} \beta^{t} \log \left(C_{t}\right)\right\} .
$$

Households have a unit measure of household members each of whom searches for a job,

$$
H_{t}=1 \text {. }
$$

I will amend the production technology from Section 4 by allowing the firm to allocate workers to one of two activities; recruiting or production. The social planner in this economy will direct the firm to allocate $V_{t}$ workers to recruiting and the remaining $X_{t}$ workers to production. The total measure of workers employed in the representative firm is the sum of these two quantities;

$$
L_{t}=X_{t}+V_{t} .
$$

Given this allocation, the firm will produce

$$
C_{t}=\left(S_{t} X_{t}\right)^{b} K_{t}^{a},
$$

units of goods and since I assume that $K_{t}=1$, this simplifies to

$$
C_{t}=\left(S_{t} L_{t}\right)^{b} .
$$

To move workers into jobs, the social planner must employ the search 
technology

$$
L_{t}=\left(\Gamma V_{t}\right)^{1 / 2} H_{t}^{1 / 2},
$$

where $\Gamma$ is a parameter that measure the efficiency of the recruiting technology. I make the strong assumption that every period, the entire workforce is fired and must be rehired the following period. ${ }^{4}$

Since the firm begins the period with no workers, and since workers are an essential input to recruiting, it might be argued that the firm can never successfully hire a worker. Since I will be thinking of the time period of the model as a quarter or a year, this assumption should be seen as a convenient way of representing the equilibrium of a dynamic process. The planner chooses a feasible 4-tuple $\{V, C, L, X\}$ and Equations (28) - (31) describe the set of feasible plans.

The cost to the firm of hiring new workers is measured in labor units, rather than output, in contrast to most search models. This innovation to the standard search model is not important and is made for expositional simplicity.

\section{The Solution to the Social Planning Prob- lem}

In this economy there is a representative agent and no way of transferring resources from one period to the next. It follows that the task of the social planner is to maximize output per person in every period by efficiently allocating workers between recruiting and production.

Combining equations (28), (30) and (31), leads to the reduced form pro-

\footnotetext{
${ }^{4}$ If I did not make this assumption, employment would become a state variable and the description of the dynamics of equilibria would become more involved. It is not too difficult to work out what happens in this case but since it complicates the algebra without adding insight, I have dispensed with that complication here.
} 
duction function

$$
C_{t}=\left[\left(S_{t} L_{t}\right)\left(1-\frac{L_{t}}{\Gamma}\right)\right]^{b} .
$$

Maximizing consumption in every period causes the social planner to choose to employ $L_{t}^{*}$ workers, where

$$
L_{t}^{*}=\frac{\Gamma}{2} .
$$

The remaining workers will be unemployed and the socially optimal unemployment rate in this economy is equal to

$$
U_{t}^{*}=1-\frac{\Gamma}{2}
$$

$U_{t}^{*}$ is a natural candidate in this economy for the natural rate of unemployment. $^{5}$

\section{Households in a Search Model}

The household sector is unaltered from the classical model with the exception that households now face a trivial labor supply decision. Households maximize utility,

$$
J=E_{0}\left\{\sum_{t=0}^{\infty} \beta^{t} \log \left(C_{t}\right)\right\},
$$

subject to the constraints

$$
\begin{gathered}
A_{t+1}+p_{t} C_{t} \leq\left(1+i_{t-1}\right) A_{t}+w_{t} L_{t}, \\
H_{t} \leq 1, \\
L_{t}=\tilde{q}_{t} H_{t},
\end{gathered}
$$

\footnotetext{
${ }^{5}$ Milton Friedman defined the natural rate of unemployment as the equilibrium rate in an economy that accounts for search frictions. That is not an appropriate definition in this economy since, as we will see, there may be a continuum of equilibrium rates only one of which coincides with the planning optimum.
} 
and the requirement that wealth is bounded. Equation (38) represents the assumption that if $H_{t}$ workers search, $\tilde{q}_{t} H_{t}$ of them will find a job where the fraction $\tilde{q}_{t}$ is determined in equilibrium by the aggregate search technology.

Since leisure does not yield disutility, households will choose,

$$
H_{t}=1 \text {. }
$$

In addition, the household will allocate assets through time optimally. That assumption leads to the same consumption Euler equation as the competitive model,

$$
\frac{1}{C_{t}}=E_{t}\left\{\beta \frac{1}{C_{t+1}}\left(1+i_{t}\right)\right\} .
$$

Since the household may also choose to invest in physical capital, the no arbitrage condition must also hold,

$$
\left(1+i_{t}\right) E_{t}\left\{\frac{1}{C_{t+1}} \frac{p_{t}}{p_{t+1}}\right\}=E_{t}\left\{\frac{1}{C_{t+1}} \frac{p_{t}}{p_{t+1}}\left(\frac{p_{k, t+1}+r r_{t+1}}{p_{k, t}}\right)\right\}
$$

\section{$9 \quad$ Firms in a Search Model}

Each firm solves the following problem,

$$
\max _{\left\{K_{t}, V_{t}, X_{t}, L_{t}\right\}}\left(S_{t} X_{t}\right)^{b} K_{t}^{a}-\frac{w_{t}}{p_{t}} L_{t}-\frac{r r_{t}}{p_{t}} K_{t}
$$

subject to the constraints,

$$
\begin{gathered}
L_{t}=X_{t}+V_{t}, \\
L_{t}=q_{t} V_{t} .
\end{gathered}
$$

The money price $p_{t}$, the money wage $w_{t}$ and the money rental rate $r r_{t}$ are taken as given. In addition, the firm takes the search efficiency of a recruiter, $q_{t}$ as given.

Think of the recruiting process as follows. The firm can attract as many 
job applicants as it desires at the wage $w_{t}$, but not all job applicants are well matched to the firm. Suitable workers must be screened by the personnel department. The variable $q_{t}^{-1}$ represents screening costs. If $q_{t}$ is high, then screening costs are low and a given pool of job applicants will yield more workers that are well matched to the firm. If $q_{t}$ is low then screening costs are high and a given pool of job applicants will yield fewer suitable workers. The firm decides on the number of applicants to process by choosing the size of its recruiting department, $V_{t}$.

This story is a simple extension of the usual description of a competitive labor market. As in the competitive model, the firm can choose to hire as many workers as it needs at the competitive wage. If a firm were to offer less than the competitive wage it would receive no applications. It has no incentive to offer a higher wage since the match quality of applicants is independent of the wage. The variable, $q_{t}$, which is taken parametrically by each firm, represents the number of workers that will be hired, after screening, by a single worker allocated to the recruiting department and it is analogous to the labor market tightness variable in a standard search model.

We can use equations (42) - (44) to derive a reduced form problem for the firm that resembles that of the firm in a neoclassical model. Substituting equations (43) and (44) into (42) and defining

$$
\Theta_{t}=\left(1-1 / q_{t}\right),
$$

we arrive at the following expression for the profit of a typical firm,

$$
\Theta_{t}^{b}\left(S_{t} L_{t}\right)^{b} K_{t}^{a}-\frac{w_{t}}{p_{t}} L_{t}-\frac{r r_{t}}{p_{t}} K_{t} .
$$

This expression is maximized when

$$
a C_{t}=\frac{r r_{t}}{p_{t}} K_{t},
$$


and

$$
b C_{t}=\frac{w_{t}}{p_{t}} L_{t}
$$

Notice that equations (47) and (48) are the same as those that would hold in a perfectly competitive labor market. They represent the two first order conditions for profit maximization. The model differs from a competitive model since the recruiting efficiency parameter $\Theta_{t}$ is endogenously determined by aggregate economic activity but is taken parametrically by the firm. I will show below that this externality allows the model to display a continuum of search equilibria each of which is consistent with profit maximization by individual firms and optimizing behavior by forward looking households with rational expectations.

\section{Search Equilibrium}

The variables $\Theta_{t}, \tilde{q}_{t}$ and $q_{t}$, are determined in equilibrium by market clearing in the markets for search inputs. To see how this works, it helps if we place a bar over a variable to represent its aggregate value. For example, $\bar{L}_{t}$ is the measure of aggregate employment and $L_{t}$ is the measure of workers hired by the average firm. These variables are conceptually distinct although they turn out to be equal in equilibrium.

Using this notation and recognizing that everybody will look for a job, Equation (31) implies that in aggregate,

$$
\bar{V}_{t}=\frac{\bar{L}_{t}^{2}}{\Gamma}
$$

This equation represents the relationship between recruiters and the number of workers hired in the economy as a whole. Each individual firm assumes instead that the following relationship holds between its own recruiting effort 
$V_{t}$ and the number of workers that it can hire,

$$
q_{t} V_{t}=L_{t}
$$

If we impose the symmetric equilibrium assumption, $L_{t}=\bar{L}_{t}$ and $V_{t}=\bar{V}_{t}$, it follows that $q_{t}$ is related to aggregate employment by the expression

$$
q_{t}=\frac{\Gamma}{\bar{L}_{t}},
$$

and $\Theta_{t}$ is determined by the expression,

$$
\Theta_{t}=\left(1-\frac{\bar{L}_{t}}{\Gamma}\right)
$$

A similar calculation for households gives the value of $\tilde{q}_{t}$

$$
\tilde{q}_{t}=\bar{L}_{t}
$$

Equation (52) defines a term, $\Theta_{t}$, that looks like a productivity shock but is in fact a recruiting externality. Some intuition may be helpful at this point.

In this model, there is a continuum of labor market equilibria. In a high unemployment equilibrium, $\Theta_{t}$ and the real wage are both high. The productivity of a recruiter is high because all firms allocate a small fraction of employed workers to recruiting and congestion effects are small.

In a low unemployment equilibrium, $\Theta_{t}$ and the real wage are both low. The productivity of a recruiter is low because all firms allocate a large fraction of employed workers to recruiting and congestion effects are large. 


\section{Characterizing Equilibrium}

How do the equations of the old-Keynesian model compare with those of the competitive economy? The following four equations are common to both models.

$$
\begin{gathered}
\frac{1}{C_{t}}=\beta E_{t}\left\{\frac{1}{C_{t+1}} \frac{p_{t}}{p_{t+1}}\left(1+i_{t}\right)\right\}, \\
\left(1+i_{t}\right) E_{t}\left\{\frac{1}{C_{t+1}} \frac{p_{t}}{p_{t+1}}\right\}=E_{t}\left\{\frac{1}{C_{t+1}} \frac{p_{t}}{p_{t+1}}\left(\frac{p_{k, t+1}+r r_{t+1}}{p_{k, t}}\right)\right\}, \\
\frac{r r_{t+1}}{p_{t+1}}=a C_{t+1}, \\
b \frac{C_{t}}{L_{t}}=\frac{w_{t}}{p_{t}} .
\end{gathered}
$$

These are the consumption Euler equation, (54), the no arbitrage equation (55), and the first order conditions for capital and labor, (56) and (57). But in the search economy, there is no labor supply equation and the production function is modified to account for the search externality,

$$
C_{t}=\left(S_{t} L_{t}\right)^{b}\left(1-\frac{L_{t}}{\Gamma}\right)^{b} .
$$

This externality is represented by the term,

$$
\left(1-\frac{L_{t}}{\Gamma}\right)^{b}
$$

\section{Closing the Model with Bargaining}

The search model has five equations, (54) - (58) to determine the six unknowns,

$$
\left\{C_{t}, \quad\left(1+i_{t}\right) \frac{p_{t}}{p_{t+1}}, \frac{w_{t}}{p_{t}}, \frac{p_{k, t}}{p_{t}}, L_{t}, \frac{r r_{t}}{p_{t}}\right\} .
$$


The missing equation arises from the absence of markets to allocate search intensity between the time of searching workers and the recruiting activities of firms, a point first made by Greenwald and Stiglitz (1988). To fill this void, it has been usual for search theorists to complete the model by assuming that, when a worker meets a firm, the worker and the firm bargain over the surplus of a match. Since the worker has no reservation disutility, the surplus to a worker is equal to the real wage,

$$
S^{W}=\frac{w_{t}}{p_{t}}
$$

The surplus of an extra production worker to the firm is the expression

$$
S^{F}=\frac{b C_{t}}{X_{t}}-\frac{w_{t}}{p_{t}}
$$

If we assume that the firm pays its recruiting workers in advance and bargains over the surplus with its production workers to solve the problem, ${ }^{6}$

$$
\max _{\frac{w_{t}}{p_{t}}}\left(\frac{b C_{t}}{X_{t}}-\frac{w_{t}}{p_{t}}\right)^{\lambda}\left(\frac{w_{t}}{p_{t}}\right)^{1-\lambda}
$$

we arrive at the following expression,

$$
\frac{w_{t}}{p_{t}}=\frac{(1-\lambda) b C_{t}}{X_{t}}
$$

Solving the free entry condition

$$
\pi_{t}=C_{t}-\frac{w}{p_{t}} X_{t}-\frac{w_{t}}{p_{t}} V_{t}-r r_{t}=0
$$

\footnotetext{
${ }^{6}$ This assumption makes the current problem comparable with standard bargaining theories in which firms pay a fixed cost to post a vacancy.
} 
for $V_{t}$, and using the fact that the capital market is competitive gives the following expression for employment,

$$
\frac{L_{t}}{\Gamma}=\lambda
$$

In words, employment is equal to the bargaining weight of the firm. If the bargaining weight $\lambda$, is equal to the elasticity of the matching function, equal to $1 / 2$ in this example, the well known Hosios (1990) condition holds and the bargaining solution is efficient.

\section{Closing the Model with Beliefs}

In this paper I propose a different solution to the indeterminacy problem. I see no reason to treat the search model differently from any other competitive model with externalities and I view the addition of the bargaining equation as arbitrary. Instead I propose to use the model of the labor market that I have described to explore the idea that market psychology, Keynes called this animal spirits, can exert an independent influence on economic activity.

In any model with rational agents, the value of an asset will equal the net present value of the flows that arise from owning it. This must be true in the old-Keynesian model just as it is true in the classical model. Combining equations (54) - (56) and solving iteratively leads to the same expression that we derived in the competitive economy,

$$
p_{k, t}=\frac{\beta r r_{t}}{(1-\beta)} .
$$

If we associate $p_{k, t}$ with the value of the stock market and $r r_{t}$ with the value of dividends, Equation (67) represents a familiar asset pricing relationship. In a classical model, the stock market fluctuates as rational, forward looking individuals estimate the fundamental value of the net present value of their dividends. In the old-Keynesian model I will argue that the direction of 
causation for this relationship is reversed.

According to an often cited passage in The General Theory, the stock market is like a beauty contest in which the judges must judge, not the beauty of the individual contestants, but how they think the other judges will rank them. One possible interpretation of that idea, in conjunction with the search model I have described, is that real labor market outcomes are determined by self-fulfilling beliefs. To represent this idea, I propose to close the search model with the assumption

$$
E_{t}\left[\frac{p_{k, t+1}}{p_{t+1}}\right]=x_{t},
$$

where $x_{t}$ is a process that represents how beliefs are influenced by economic events.

$x_{t}$ could be determined in a variety of ways. It plays a similar role in this model to that of government expenditure or taxes in a conventional macroeconomic model. It is typical to treat those variables as exogenous although there are clearly feedback effects from the economy to the political process. As economists we often treat those effects as the domain of political scientists. By analogy, I see $x_{t}$ as capturing the role of psychology on the stock market. Different models for the evolution of beliefs will have different implications for the behavior of all of the endogenous variables of the model.

Table 1 compares the old-Keynesian model with the classical model and with a search model closed with the Nash Bargaining assumption. Equations (T1) through (T4) in Table 1 are the same in all three models. In the two search models the technology, Equation (T5), differs from the competitive model to reflect the presence of recruiting externalities. Equation (T6) compares the competitive labor supply equation with two alternative ways of closing the search model. In the bargaining model, employment is constant in equilibrium as it is in the competitive model. ${ }^{7}$ In the old-Keynesian

\footnotetext{
${ }^{7}$ To see this, compare Equation (T3) with the bargaining version of Equation (T6).
} 
search model employment may vary in response to both productivity shocks and belief shocks.

\begin{tabular}{|c|c|}
\hline Table 1: & Equations in Common \\
\hline$(\mathrm{T} 1)$ & $\frac{1}{C_{t}}=\beta E_{t}\left\{\frac{1}{C_{t+1}} \frac{p_{t}}{p_{t+1}}\left(1+i_{t}\right)\right\}$ \\
\hline$(\mathrm{T} 2)$ & $\left(1+i_{t}\right) E_{t}\left\{\frac{1}{C_{t+1}} \frac{p_{t}}{p_{t+1}}\right\}=E_{t}\left\{\frac{1}{C_{t+1}} \frac{p_{t}}{p_{t+1}}\left(\frac{p_{k, t+1}+r r_{t+1}}{p_{k, t}}\right)\right\}$ \\
\hline (T3) & $b \frac{C_{t}}{L_{t}}=\frac{w_{t}}{p_{t}}$ \\
\hline \multirow[t]{4}{*}{$(\mathrm{T} 4)$} & $\frac{r r_{t+1}}{p_{t}}=a C_{t+1}$ \\
\hline & Equations that Differ \\
\hline & Old Keynesian \\
\hline & Search Model \\
\hline$(\mathrm{T} 5)$ & $C_{t}=\left(S_{t} L_{t}\right)^{b}\left(1-\frac{L_{t}}{\Gamma}\right) \quad C_{t}=\left(S_{t} L_{t}\right)^{b}\left(1-\frac{L_{t}}{\Gamma}\right)$ \\
\hline$(\mathrm{T} 6)$ & $\frac{b(1-\lambda) C_{t}}{L_{t}\left(1-L_{t} / \Gamma\right)}=\frac{w_{t}}{p_{t}} \quad E_{t}\left[\frac{p_{k, t+1}}{p_{t+1}}\right]=x_{t}$ \\
\hline
\end{tabular}

How do these three models compare in their empirical predictions? That depends on how we model the variable $x_{t}$. One might, for example, assume that

$$
x_{t}=\frac{p_{k, t}}{p_{t}} \exp \left(\varepsilon_{t}\right)
$$

where $\varepsilon_{t}$ is an iid random variable with zero mean. In that case, the model predicts that real value of the stock market is a martingale simply because people believe that it will be so. If expectations are rational then $p_{k, t} / p_{t}$ will follow a random walk, driven by beliefs. Since

$$
C_{t}=\frac{1}{\theta} \frac{p_{k, t}}{p_{t}}
$$

the assumption that wealth follows an independent process leads to a model where real GDP is driven by wealth fluctuations that themselves arise from beliefs about asset values. Employment in this version of the model would 
be driven by the equation

$$
L_{t}=\frac{1}{S_{t}}\left(\left[\frac{p_{k, t}}{\theta p_{t}} \exp \left(\varepsilon_{t}\right)\right]\right)^{\frac{1}{b}}
$$

where $S_{t}$ represents productivity shocks and $\varepsilon_{t}$ are belief shocks. In the oldKeynesian model, driven by beliefs, employment will fluctuate in response to both belief shocks and productivity shocks. Equation (71) demonstrates that, if beliefs are independent of productivity shocks, employment will be negatively correlated with productivity. More generally, one might expect that fundamental events will influence the value of the stock market through Equation (69). By specifying the nature of that dependence, the model is capable of capturing any observed correlation between productivity and employment. In contrast, the classical model and the bargaining model both lead to constant employment.

Could one devise an empirical test to distinguish the belief driven model from its classical and bargaining counterparts? I am skeptical. Certainly any given model of belief formation can be rejected by the data. And in that sense the theory, once supplemented by a specification of beliefs, has bite. But the class of all belief driven models cannot perform worse than any given bargaining model since there will always exist a function which describes how beliefs are formed that makes the two theories observationally equivalent.

For example, in the bargaining version of the search model, $L_{t}$ is constant and given by the expression

$$
\frac{L_{t}}{\Gamma}=\lambda
$$

It follows from the other equations of the model that the real value of the stock market will be described by the process

$$
\frac{p_{k, t}}{p_{t}}=\theta\left(S_{t} \Gamma \lambda\right)^{b}
$$

By choosing equation (73) as an independent driving equation that describes 
the formation of beliefs, the old-Keynesian model will mimic exactly, the behavior of the bargaining model. If one is willing to treat the bargaining parameter $\lambda$, as time dependent, the reverse is also true. Any process for beliefs in the old-Keyensian model implies a sequences of bargaining weights $\left\{\lambda_{t}\right\}$ that makes the two models observationally equivalent.

\section{Why I Favor the Old-Keynesian Model}

The old-Keynesian model that I have described cannot be directly compared with the workhorse real business cycle model, (RBC), because I have abstracted from investment in the models described in this paper. I made this choice because the intertemporal substitution mechanism that drives employment fluctuations in the RBC model is not necessary to understand employment variations in the old-Keynesian model. And since the canonical RBC model has only one good, the relative price of the capital good in terms of the consumption good is always equal to one. That is not a good model to discuss the relationship of stock market valuation with unemployment.

Why am I interested in that comparison? Because there is a close correlation between the value of the stock market and the value of unemployment during major recessions. Figures 1 and 2 compare the dollar value of the S\&P 500 and the unemployment rate over two different decades. Figure 1 covers the period from January 1928 through December 1939 and Figure 2 is from December of 2001 through December of 2010. In both figures the unemployment rate is graphed on the right axis on an inverted scale and the $\mathrm{S} \& \mathrm{P}$ is graphed as an index number on the left scale. NBER recessions appear as shaded regions. 


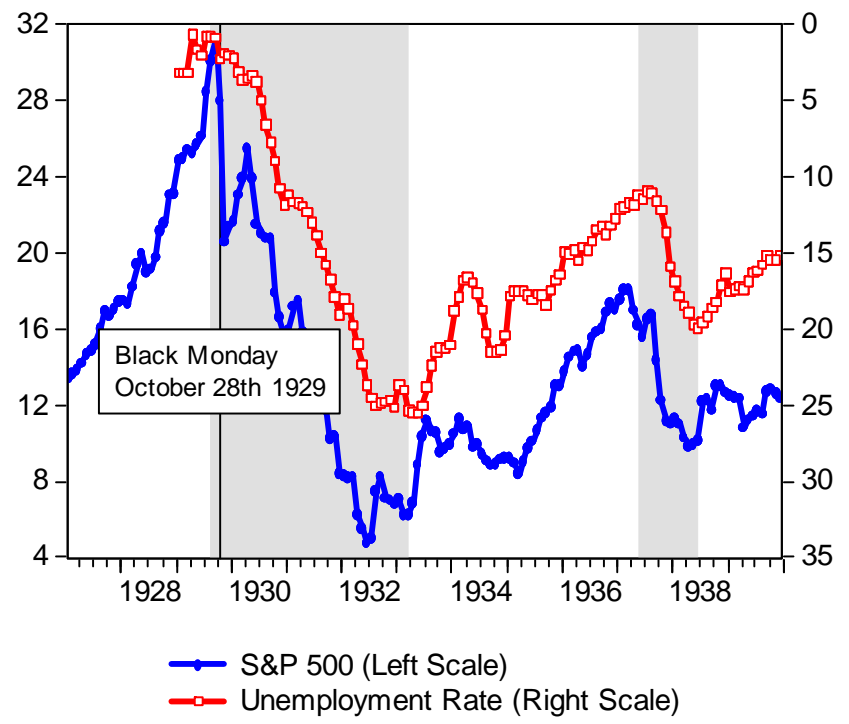

Figure 1: Unemployment and the Stock Market During the Great Depression

I realize that correlation is not causation and these graphs do not prove that the stock market crash caused the Great Depression. However, they do suggest to me that a theory that does make that causal link deserves further consideration. Old-Keynesian economics is one such theory. The bargaining model of search and the classical labor market with logarithmic preferences both predict that labor hours will be constant and cannot account for these data. 


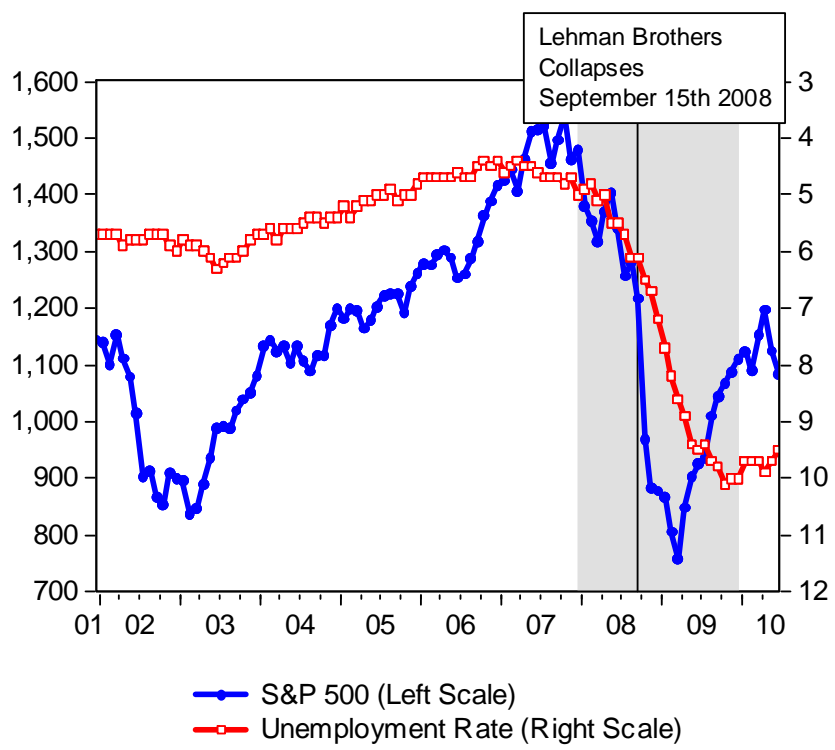

Figure 2: Unemployment and the Stock Market over the Last Decade

A critic might respond that it is unfair to compare the old-Keynesian model with a classical model that abstracts from investment since the intertemporal substitution mechanism has been shut down in that model. In the RBC economy labor hours fluctuate because households voluntarily choose to work harder during booms.

While that is a fair point, I would respond that replacing the competitive labor market of that model, with the old-Keynesian search model, cannot possibly perform worse than the competitive labor market model since there is a specification for beliefs under which the two models make the same predictions. Further, the extent to which the RBC model fails badly is connected with the implausibility of the labor supply equation which forces hours worked and consumption to move in opposite directions as long as leisure is a normal good (Mankiw, Rotemberg, and Summers, 1985). That is precisely the equation that I have removed by adding a model of search.

Perhaps the RBC model is the wrong alternative. Much progress has been made recently on search models with sticky wages and those models behave 
much like the one discussed in this paper. But recent work that estimates a model in this class by Gali, Smets, and Wouters (2010) finds an important role for wage markup shocks in estimated data. The model studied by these authors is closest to the bargaining model of search that I described in this paper.

The Gali-Smets-Wouters model is a close cousin of the bargaining version of the labor search model. In that model, Gali-Smets-Wouters' wage markup shock would be represented as a shock to the bargaining weight. Since the model with time varying bargaining weights is isomorphic to the oldKeynesian model why should one prefer one model over the other? In both models one would observe that a stock market crash is correlated with a drop in employment and a shift in the bargaining weight. But in the absence of a good theory of why the bargaining weight shifted dramatically in 1929 and again in 2008 I find it more plausible to think that the direction of causation in both cases was from self-fulfilling beliefs in the asset markets to a drop in aggregate demand.

Two papers have estimated versions of the old-Keynesian model. Gelain and Guerrazzi (2010) use Bayesian methods to estimate a version of the Old-Keynesian model due to Guerrazzi (2010) on both US and European data with encouraging results. Farmer (2010a) compares a three equation monetary version of the old-Keynesian model with a three equation newKeynesian model. Farmer's estimates of the old-Keynesian model replace the Phillips curve with a belief function that describes the evolution of selffulfilling beliefs about nominal income growth. He compares the posterior odds ratio for the two specifications and finds that the old-Keynesian model outperforms the new-Keynesian model. The reason for this improved fit is the ability of the old-Keynesian model to explain persistent unemployment as a demand driven phenomenon. There is a version of the new-Keynesian model that will perform as well, but it requires one to assume that persistent movements in the unemployment rate are caused by changes in the prefer- 
ences of households for leisure. In other words, the new-Keynesian model can only capture persistence of the unemployment rate if it is the natural rate of unemployment that is moving over time.

\section{Conclusion}

In this paper I have argued that, in modern market economies, it is costly to match unemployed workers with vacant jobs. Because there are no markets for the search time of unemployed workers or the search time of corporate recruiters, free market economies do not provide the necessary price signals to ensure that a given number of jobs is filled in the right way. Because the relevant price signals are missing, a market economy can become stuck in an equilibrium with a high unemployment rate. There are many such equilibria and almost all of them are socially inefficient.

In the model of the paper, firms decide how many workers to hire based on the demand for the goods that they produce. The demand for goods depends on wealth and every wealth level is associated with a different equilibrium unemployment rate and a different set of prices for factories and machines. The value of these physical assets depends on what market participants think they will be worth in the future.

This paradigm provides us with a new way to think about large recessions like the Great Depression and the Great Recession of 2007-2009. Using the model from this paper I would argue that the world economy in 2008 was headed rapidly towards a high unemployment, low wealth, equilibrium. The move to this bad equilibrium was triggered by a loss of confidence in the value of assets, backed by mortgages in the US subprime mortgage market. The inability to value these assets led to an amplification of the crisis as panic hit the global financial markets.

In the winter of 2011, the US labor market had still not recovered. I believe that much of the problem is connected with a lack of confidence by 
global investors who are concerned with the possibility of a further collapse. Even though the US stock market may be appropriately valued based on historical price earnings ratios - market participants are concerned that the value of stocks could fall further. Variations in the level of confidence are manifested in changing risk premia that are fully rational given the unpredictable behavior of future traders in the asset markets. Recognizing the nature of a problem is a first, and necessary step, towards finding its solution. I hope, in this paper, to have made a contribution to this first step. 


\section{References}

Diamond, P. A. (1982a): "Aggregate Demand Management in Search Equilibrium," Journal of Political Economy, 90, 881-94.

- (1982b): "Wage determination and efficiency in search equilibrium," Review of Economic Studies, 49, 217-227.

— (1984): "Money in Search Equilibrium," Econometrica, 52, 1-20.

FARMer, R. E. A. (2008a): "Aggregate Demand and Supply," International Journal of Economic Theory, 4(1), 77-94.

- (2008b): "Old Keynesian Economics," in Macroeconomics in the Small and the Large, ed. by R. E. A. Farmer, chap. 2. Edward Elgar, Cheltenham, UK.

- (2010a): "Animal Spirits, Persistent Unemployment and the Belief Function," NBER Working Paper 16522.

(2010b): Expectations, Employment and Prices. Oxford University Press, New York.

- (2010c): "How to Reduce Unemployment: A New Policy Proposal," Journal of Monetary Economics: Carnegie Rochester Conference Issue, $57(5), 557-572$.

Farmer, R. E. A., And A. Hollenhorst (2004): "Shooting the Auctioneer," UCLA mimeo.

Farmer, R. E. A., and D. Plotnikov (2010): "Does Fiscal Policy Matter? Blinder and Solow Revisited," UCLA mimeo (working paper version).

Gali, J., F. Smets, and R. Wouters (2010): "Unemployment in an Estimated New Keynesian Model," Working Paper CREI. 
Gelain, P., and M. Guerrazzi (2010): "A DSGE Model from the Old Keynesian Economics: An Empirical Investigation," University of St. Andrews; Centre for Dynamic Macroeconomic Analysis Working Paper Series, CDMA10/14.

Gertler, M., L. Sala, and A. Trigari (2008): "An Estimated DSGE Model with Unemployment and Staggered Wage Bargaining," Journal of Money Credit and Banking, 40(8), 1713-1764.

Gertler, M., and A. Trigari (2009): "Unemployent Fluctuations with Staggered Nash Wage Bargaining," Journal of Political Economy, 117(1), 38-86.

Greenwald, B., And J. E. Stiglitz (1988): "Pareto Inefficiency of Market Economies: Search and Efficiency Wage Models," American Economic Review, 78(2), 352-355.

Guerrazzi, M. (2010): "Stochastic Dynamic Matching in the Old Keynesian Economics: A Rationale for Shimer's Puzzle," Discussion Paper del Dipartimento di Scienze Economiche - Univertsita di Pisa, No. 95.

Hagedorn, M., And I. Manovskit (2008): "The Cyclical Behavior of Equilibrium Unemployment and Vacancies Revisited," American Economic Review, 98(4), 1692-1706.

Hall, R. E. (2005a): "Employment Efficiency and Sticky Wages: Evidence from Flows in the Labor Market," The Review of Economics and Statistics, $87(3), 397-407$.

Hall, R. E. (2005b): "Employment Fluctuations with Equilibrium Wage Stickiness," American Economic Review, 95(1), 50-65.

Hall, R. E., And P. Milgrom (2008): "The Limited Influence of Unemployment on the Wage Bargain," American Economic Review, 98(4), $1653-1674$. 
Hansen, A. (1936): "Mr. Keynes on Underemployment Equilibrium," Journal of Political Economy, 44(5), 667-686.

Hicks, J. R. (1937): "Mr. Keynes and the Classics: A Suggested Interpretation," Econometrica, 5(2), 147-159.

Hosios, A. (1990): "On the efficiency of matching and related models of search and unemployment," Review of Economic Studies, 57, 279-298.

Howitt, P., And R. P. McAfee (1987): "Costly Search and Recruiting," International Economic Review, 28(1), 89-107.

Keynes, J. M. (1936): The General Theory of Employment, Interest and Money. MacMillan and Co.

Mankiw, N. G., J. J. Rotemberg, and L. H. Summers (1985): "Intertemporal Substitution in Macroeconomics," Qaurterly Journal of Economics, 100(1), 225-251.

Mortensen, D. T. (1984): "The Matching Process as a Non-Cooperative Bargaining Games," in The Economics of Information and Uncertainty, ed. by J. J. McCall, pp. 233-254, Chicago. University of Chicago Press for NBER.

Pissarides, C. (1984): "Search Intensity, Job Advertising and Efficiency," Journal of Labor Economics, 2, 128-143.

Samuelson, P. A. (1955): Economics: An Introductory Analysis (3rd Ed.). McGraw Hill.

Shimer, R. (2005): "The Cyclical Behavior of Equilibrium Unemployment and Vacancies," American Economic Review, 95(1), 25-49. 